\title{
COLLEGE of AMERICAN PATHOLOGISTS
}

\section{Protocol for the Examination of Radical Prostatectomy Specimens From Patients With Carcinoma of the Prostate Gland}

\author{
Version: Prostate Radical Prostatectomy 4.0.4.1 Protocol Posting Date: August 2019
}

CAP Laboratory Accreditation Program Protocol Required Use Date: May 2020

Includes PTNM requirements from the $8^{\text {th }}$ Edition, AJCC Staging Manual

For accreditation purposes, this protocol should be used for the following procedures AND tumor types:

\begin{tabular}{|l|l|}
\hline Procedure & Description \\
\hline Prostatectomy & Includes specimens designated radical prostatectomy \\
\hline Tumor Type & Description \\
\hline Carcinoma & $\begin{array}{l}\text { Includes all adenocarcinomas and histologic variants, neuroendocrine } \\
\text { carcinomas, and other types. }\end{array}$ \\
\hline
\end{tabular}

This protocol is NOT required for accreditation purposes for the following:

\begin{tabular}{|l|}
\hline Procedure \\
\hline Transurethral resection of the prostate (TURP) (consider Prostate TURP protocol) \\
\hline Biopsy (consider the Prostate Biopsy protocol) \\
\hline Primary resection specimen with no residual cancer (eg, following neoadjuvant therapy) \\
\hline Cytologic specimens \\
\hline
\end{tabular}

The following tumor types should NOT be reported using this protocol:

\begin{tabular}{|l|}
\hline Tumor Type \\
\hline Urothelial tumor, including variants (consider the Urethra (prostatic urethra) protocol) \\
\hline Lymphoma (consider the Hodgkin or non-Hodgkin Lymphoma protocols) \\
\hline Sarcoma (consider the Soft Tissue protocol) \\
\hline
\end{tabular}

\section{Authors}

Gladell P. Paner, MD*; John R. Srigley, MD*; Ming Zhou, MD, PhD*; Robert Allan, MD; Mahul B. Amin, MD; Sam S. Chang, MD; Brett Delahunt, MD; Lars Egevad, MD; Jonathan I. Epstein, MD; Andrew J. Evans, MD; David J. Grignon, MD; Peter A. Humphrey, MD, PhD; James M. McKiernan, MD; Rodolfo Montironi, MD; Jason Pettus, MD; Victor E. Reuter, MD; Thomas M. Wheeler, MD

With guidance from the CAP Cancer and CAP Pathology Electronic Reporting Committees.

* Denotes primary author. All other contributing authors are listed alphabetically. 


\section{Accreditation Requirements}

This protocol can be utilized for a variety of procedures and tumor types for clinical care purposes. For accreditation purposes, only the definitive primary cancer resection specimen is required to have the core and conditional data elements reported in a synoptic format.

- $\quad$ Core data elements are required in reports to adequately describe appropriate malignancies. For accreditation purposes, essential data elements must be reported in all instances, even if the response is "not applicable" or "cannot be determined."

- Conditional data elements are only required to be reported if applicable as delineated in the protocol. For instance, the total number of lymph nodes examined must be reported, but only if nodes are present in the specimen.

- Optional data elements are identified with "+" and although not required for CAP accreditation purposes, may be considered for reporting as determined by local practice standards.

The use of this protocol is not required for recurrent tumors or for metastatic tumors that are resected at a different time than the primary tumor. Use of this protocol is also not required for pathology reviews performed at a second institution (ie, secondary consultation, second opinion, or review of outside case at second institution).

\section{Synoptic Reporting}

All core and conditionally required data elements outlined on the surgical case summary from this cancer protocol must be displayed in synoptic report format. Synoptic format is defined as:

- Data element: followed by its answer (response), outline format without the paired "Data element:

Response" format is NOT considered synoptic.

- The data element should be represented in the report as it is listed in the case summary. The response for any data element may be modified from those listed in the case summary, including "Cannot be determined" if appropriate.

- Each diagnostic parameter pair (Data element: Response) is listed on a separate line or in a tabular format to achieve visual separation. The following exceptions are allowed to be listed on one line:

o Anatomic site or specimen, laterality, and procedure

o Pathologic Stage Classification (pTNM) elements

o Negative margins, as long as all negative margins are specifically enumerated where applicable

- The synoptic portion of the report can appear in the diagnosis section of the pathology report, at the end of the report or in a separate section, but all Data element: Responses must be listed together in one location Organizations and pathologists may choose to list the required elements in any order, use additional methods in order to enhance or achieve visual separation, or add optional items within the synoptic report. The report may have required elements in a summary format elsewhere in the report IN ADDITION TO but not as replacement for the synoptic report ie, all required elements must be in the synoptic portion of the report in the format defined above.

\section{CAP Prostate Protocol Summary of Changes}

\section{Version 4.0.4.1}

Removed footnote for $\mathrm{pT}$ related to "R" 


\section{Surgical Pathology Cancer Case Summary}

Protocol posting date: August 2019

PROSTATE GLAND: Radical Prostatectomy

Select a single response unless otherwise indicated.

Procedure (Note A)

Radical prostatectomy

Other (specify):

Not specified

+Prostate Size (Note A)

+ Weight: (grams)

+ Size (centimeters): $\mathrm{x}$ $\mathrm{cm}$

Histologic Type (select all that apply) (Note B)

Acinar adenocarcinoma

Ductal adenocarcinoma

Small-cell neuroendocrine carcinoma

Other histologic type not listed (specify):

Histologic Grade (select all that apply) (Note C)

Grade Group and Gleason Score

Not applicable

Cannot be assessed

Grade group 1 (Gleason Score 3+3=6)

Grade group 2 (Gleason Score $3+4=7$ )

Grade group 3 (Gleason Score $4+3=7$ )

Grade group 4 (Gleason Score $4+4=8$ )

Grade group 4 (Gleason Score $3+5=8$ )

Grade group 4 (Gleason Score 5+3=8)

Grade group 5 (Gleason Score $4+5=9$ )

Grade group 5 (Gleason Score 5+4=9)

Grade group 5 (Gleason Score $5+5=10$ )

Percentage of Pattern 4 in Gleason Score $7(3+4,4+3)$ Cancer (report if applicable): __ \%

+ Percentage of Gleason Patterns 4 and 5 (applicable to Gleason score greater than 7 or 7 with a tertiary pattern 5)

+ Percentage of pattern 4: $\%$

+ Percentage of pattern $5:-\%$

+ Intraductal Carcinoma (IDC) (Note D)

$+\quad$ Not identified

+ Present

$+\ldots$ Cannot be determined 


\section{+ Tumor Quantitation (Note E)}

+ Estimated percentage of prostate involved by tumor: $\%$

\section{$\underline{A N D / O R}$}

+ Tumor size (dominant nodule, if present):

+ Greatest dimension (millimeters):

+ Additional dimensions (millimeters): $\mathrm{mm}$

+ Location of dominant nodule $\mathrm{x}$

\section{Extraprostatic Extension (EPE) (Note F)} Not identified

Present, focal

Present, nonfocal

Cannot be determined

+ Location of Extraprostatic Extension (select all that apply)

$+\ldots$ Right apical

+ R Right bladder neck

+ Right anterior

+ Right lateral

+ Right posterolateral (neurovascular bundle)

+ Right posterior

+ Left apical

+ L Left bladder neck

+ L Left anterior

+ L Left lateral

+ _ Left posterolateral (neurovascular bundle)

$+\ldots$ Left posterior

$+\ldots$ Other(s) (specify):

Urinary Bladder Neck Invasion (Note G)

Not identified

Present

\section{Seminal Vesicle Invasion (Note $\mathrm{H}$ )}

Not identified

Present

+ Right

$+\ldots$ Left

+ Bilateral

No seminal vesicle present

+ Lymphovascular Invasion

$+\ldots$ Not identified

+ Present

+ Cannot be determined

+ Perineural Invasion (Note I)

$+\ldots$ Not identified

+ P Present 


\section{Margins (Note $\mathrm{J}$ )}

Cannot be assessed

Uninvolved by invasive carcinoma

$+\quad$ Benign prostate glands present at surgical margin

Involved by invasive carcinoma Limited (less than $3 \mathrm{~mm}$ )

Non-limited (greater than or equal to $3 \mathrm{~mm}$ )

+ Linear length of positive margin(s) (millimeters):

$\mathbf{m m}$

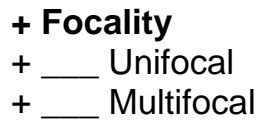

Location of Positive Margin(s) (select all that apply)

Right apical

Right bladder neck

Right anterior

Right lateral

Right postero-lateral (neurovascular bundle)

Right posterior

Left apical

Left bladder neck

Left anterior

Left lateral

Left postero-lateral (neurovascular bundle)

Left posterior

Other(s) (specify):

+ Margin Positivity in Area of Extraprostatic Extension (EPE)

$+\ldots$ Not identified

+ Present

+ Specify location(s):

+ Gleason Pattern at Positive Margin(s) (Note J)

$+\quad$ Pattern 3

+ Pattern 4

+ _ Pattern 5

Treatment Effect (select all that apply)

No known presurgical therapy

Not identified

Radiation therapy effect present

Hormonal therapy effect present

Other therapy effect(s) present (specify):

Cannot be determined

\section{Regional Lymph Nodes}

No lymph nodes submitted or found

Lymph Node Examination (required only if lymph nodes are present in the specimen)

Number of Lymph Nodes Involved:

Number cannot be determined (explain):

+ Specify Site(s):

\# Note: Sites may include hypogastric, obturator, internal iliac, external iliac, iliac NOS, pelvic NOS, lateral sacral, presacral, promontory, sacral NOS, or other lymph nodes.

+ Data elements preceded by this symbol are not required for accreditation purposes. These optional elements may be 
+ Size of Largest Metastatic Deposit (centimeters): $\mathbf{c m}$

+ Specify Site:

+ Size of Largest Lymph Node Involved (centimeters): cm

+ Specify Site:

+ Extranodal Extension

$+\ldots$ Not identified

+ Present

+ Cannot be determined

Number of Lymph Nodes Examined:

Number cannot be determined (explain):

\section{Pathologic Stage Classification (pTNM, AJCC $8^{\text {th }}$ Edition) (Note K)}

Note: Reporting of $p T, p N$, and (when applicable) $p M$ categories is based on information available to the pathologist at the time the report is issued. Only the applicable T, N, or M category is required for reporting; their definitions need not be included in the report. The categories (with modifiers when applicable) can be listed on 1 line or more than 1 line.

\section{TNM Descriptors (required only if applicable) (select all that apply)} $\mathrm{m}$ (multiple)

$r$ (recurrent)

$y$ (posttreatment)

\section{Primary Tumor (pT)}

pT2: Organ confined

pT3: Extraprostatic extension

pT3a: Extraprostatic extension (unilateral or bilateral) or microscopic invasion of bladder neck

pT3b: Tumor invades seminal vesicle(s)

pT4: Tumor is fixed or invades adjacent structures other than seminal vesicles such as external sphincter, rectum, bladder, levator muscles, and/or pelvic wall

Note: There is no pathologic T1 classification.

\section{Regional Lymph Nodes (pN)}

pNX: Regional lymph nodes cannot be assessed

pNO: No positive regional nodes

pN1: Metastases in regional node(s)

Distant Metastasis (pM) (required only if confirmed pathologically in this case)

pM1: Distant metastasis

pM1a: Nonregional lymph nodes(s)

pM1b: Bone(s)

pM1c: Other site(s) with or without bone disease

Specify site(s), if known:

\# Note: When more than one site of metastasis is present, the most advanced category is used. M1c is most advanced.

+ Additional Pathologic Findings (select all that apply)

$+\ldots$ None identified

+ High-grade prostatic intraepithelial neoplasia (PIN)

$+\ldots$ Inflammation (specify type):

+ _ Atypical adenomatous hyperplasia (adenosis)

+ Nodular prostatic hyperplasia

+ _ Other (specify):

+ Data elements preceded by this symbol are not required for accreditation purposes. These optional elements may be clinically important but are not yet validated or regularly used in patient management. 
+ Ancillary Studies

+ Specify:

$+\ldots$ Not performed

+ Comment(s) 


\title{
Explanatory Notes
}

\section{A. Submission of Tissue for Microscopic Evaluation in Radical Prostatectomy Specimens}

It is not mandatory but recommended to report the size and weight of the prostate gland as several studies have shown that men with smaller prostates had more high-grade cancers and more advanced disease and were at greater risk of progression after RP. Therefore, they may be important prognostic variables postoperatively to predict biochemical progression. A radical prostatectomy specimen may be submitted in its entirety or partially sampled in a systematic fashion. ${ }^{1-3}$ For partial sampling in the setting of a grossly visible tumor, the tumor and associated periprostatic tissue and margins, along with the entire apical and bladder neck margins and the junction of each seminal vesicle with prostate proper, should be submitted. If there is no grossly visible tumor, a number of systematic sampling strategies may be used. One that yields excellent prognostic information involves submitting the posterior aspect of each transverse slice along with a mid anterior block from each side. ${ }^{3}$ The anterior sampling detects the T1c cases arising in the transition zone and extending anteriorly. The entire apical and bladder neck margins and the junction of each seminal vesicle with the prostate should also be submitted.

\section{References}

1. Srigley JR. Key issues in handling and reporting radical prostatectomy specimens. Arch Pathol Lab Med. 2006;30:303-317.

2. Sehdev AE, Pan CC, Epstein JI. Comparative analysis of sampling methods for grossing radical prostatectomy specimens performed for nonpalpable (stage T1c) prostatic adenocarcinoma. Hum Pathol. 2001;32:494-499.

3. Samarantunga $\mathrm{H}$, Montironi R, True L, et al; The ISUP prostate consensus group. International Society of Urological Pathology (ISUP) Consensus Conference on Handling and Staging of Radical Prostatectomy Specimens: Working group 1: handling of the specimen. Mod Pathol. 2011;24:6-15.

\section{B. Histologic Type}

This protocol applies only to invasive adenocarcinomas of the prostate gland, as shown below. Carcinomas other than adenocarcinoma are exceptionally uncommon, accounting for less than $0.5 \%$ of prostatic tumors. The protocol does not apply to pure squamous cell carcinoma, basal cell carcinoma, urothelial carcinoma, small cell neuroendocrine carcinoma, and large cell neuroendocrine carcinoma. If these rare subtypes of carcinoma, however, are mixed with acinar type adenocarcinoma, the protocol may be used.

\author{
Classification of Invasive Adenocarcinoma of Prostate (2016 WHO classification ${ }^{1}$ ) \\ Acinar adenocarcinoma \\ Atrophic \\ Pseudohyperplastic \\ Microcystic \\ Foamy gland \\ Mucinous (colloid) \\ Signet ring-like cell \\ Pleomorphic giant cell \\ Sarcomatoid \\ Ductal adenocarcinoma \\ Cribriform \\ Papillary \\ Solid \\ Neuroendocrine tumors \\ Adenocarcinoma with neuroendocrine differentiation \\ Well-differentiated neuroendocrine tumor \\ Small-cell neuroendocrine carcinoma \\ Large cell neuroendocrine carcinoma
}




\section{References}

1. Humphrey P, Amin MB, Berney D, Billis A, et al. Acinar adenocarcinoma. In: Moch H, Humphrey PA, Ulbright T, Reuter VE, eds. Pathology and Genetics: Tumors of the Urinary System and Male Genital Organs. 4th edition. WHO Classification of Tumors. Zurich, Switzerland: WHO Press; 2015:3-28.

\section{Histologic Grade}

Gleason Score

The Gleason grading system is recommended for use in all prostatic specimens containing adenocarcinoma, with the exception of those showing treatment effects, usually in the setting of androgen withdrawal and radiation therapy. ${ }^{1,2}$ The Gleason score is an important parameter used in nomograms, such as the Kattan nomograms, ${ }^{3,4}$ and the Partin tables, ${ }^{5}$ which guide individual treatment decisions. Readers are referred to the recommendations of 2 ISUP consensus conferences dealing with the contemporary usage of the Gleason system (also see Figure 1). ${ }^{6,7}$ The Gleason score is the sum of the primary (most predominant in terms of surface area of involvement) Gleason grade and the secondary (second most predominant) Gleason grade. Where no secondary Gleason grade exists, the primary Gleason grade is doubled to arrive at a Gleason score. The primary and secondary grades should be reported in addition to the Gleason score, that is, Gleason score $7(3+4)$ or $7(4+3)$.

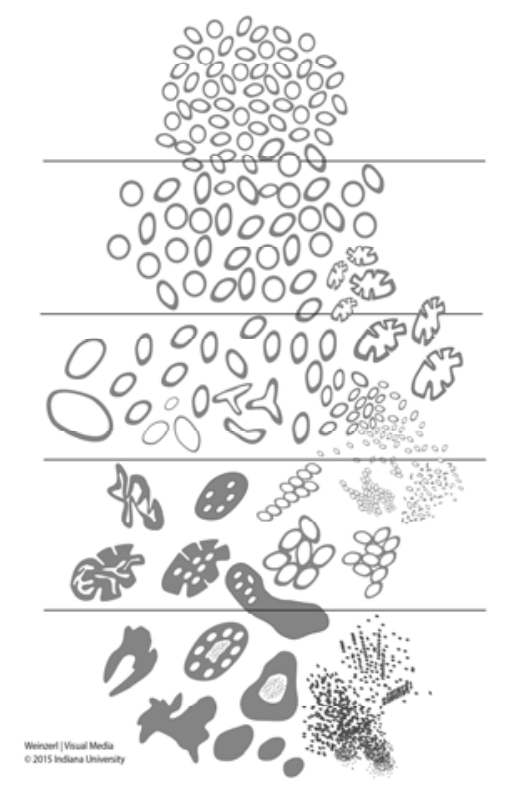

Figure 1. 2015 modified ISUP Gleason schematic diagram. ${ }^{7}$

Tertiary Gleason patterns are common in radical prostatectomy specimens. When Gleason pattern 5 is present as a tertiary pattern, its presence should be recognized in the report. ${ }^{2}$ For instance, in a situation where the primary Gleason pattern is 3, the secondary pattern is 4 , and there is less than $5 \%$ Gleason pattern 5 , the report should indicate a Gleason score of $7(3+4)$ with tertiary Gleason pattern 5 . If Gleason pattern 5 is greater than $5 \%$ and constitutes the third most common pattern, some pathologists include it as the secondary pattern, rather than as the tertiary pattern. It is also recommended to document the $\%$ of pattern 5 in these cases for future studies.

For radical prostatectomy specimens, Gleason score should be assigned to the dominant nodule(s), if present. ${ }^{6}$ In some cases, a dominant nodule is not identified, and the grading is based on all carcinomatous areas. Where more than one separate tumor is clearly identified, the Gleason scores of individual tumors can be recorded separately, or, at the very least, a Gleason score of the dominant or most significant lesion (highest Gleason score or pT category, if not the largest) should be recorded. For instance, if there is a large Gleason score $4(2+2)$ transition zone tumor and a separate smaller Gleason score $8(4+4)$ peripheral zone cancer, both scores should be reported, or, at the very least, the latter score should be reported rather than these scores being averaged. 


\section{Grade Group}

The 9 Gleason scores (2-10) have been variably lumped into different groups for prognosis and patient management purposes. Epstein and associates proposed grouping scores into 5 prognostic categories, grade groups 1-5. ${ }^{8}$ This grade grouping, shown below in the table, strongly correlate with biochemical recurrence and have been incorporated into the new Partin tables. ${ }^{8-10}$ At the 2014 ISUP Consensus Conference, details of this prognostic system were clarified and it was recommended for usage together with the Gleason system. ${ }^{7}$ This grade grouping has also been subsequently validated by other independent studies in surgical and radiation cohorts show significant correlation with survival. ${ }^{11-13}$ The new grade grouping has been endorsed in the 2016 WHO classification. ${ }^{1}$

The grade grouping has also been endorsed by ISUP and is referred to as ISUP grade in some publications. Like Gleason scoring in needle biopsies, the grade group can be applied at core, specimen, or case levels.

Table: Grade Groups

\begin{tabular}{|c|c|c|}
\hline Grade Group & Gleason Score & Definition \\
\hline 1 & $\begin{array}{l}\text { Less than or } \\
\text { equal to } 6\end{array}$ & Only individual discrete well-formed glands \\
\hline 2 & $3+4=7$ & $\begin{array}{l}\text { Predominantly well-formed glands with lesser } \\
\text { component of poorly formed/fused/cribriform glands }\end{array}$ \\
\hline 3 & $4+3=7$ & $\begin{array}{l}\text { Predominantly poorly formed/fused/cribriform glands } \\
\text { with lesser component }(\#) \text { of well-formed glands }\end{array}$ \\
\hline \multirow{3}{*}{4} & $4+4=8$ & Only poorly formed/fused/cribriform glands \\
\hline & $3+5=8$ & $\begin{array}{l}\text { Predominantly well-formed glands and lesser } \\
\text { component }\left({ }^{\prime \prime}\right) \text { lacking glands (or with necrosis) }\end{array}$ \\
\hline & $5+3=8$ & $\begin{array}{l}\text { Predominantly lacking glands (or with necrosis) and } \\
\text { lesser component }\left({ }^{\#}\right) \text { of well-formed glands }\end{array}$ \\
\hline 5 & $9-10$ & $\begin{array}{l}\text { Lack gland formation (or with necrosis) with or without } \\
\text { poorly formed/fused/cribriform glands }\left(^{\#}\right)\end{array}$ \\
\hline
\end{tabular}
\# For cases with greater than 95\% poorly formed/fused/cribriform glands on a core or at radical prostatectomy, the component
of less than $5 \%$ well-formed glands is not factored into the grade; should therefore be graded as grade group 4.

\#\# Poorly formed/fused/cribriform glands can be a more minor component.

Percentage Gleason patterns 4 and 5 (Applicable to Gleason Scores greater than or equal to 7 ) Another recommendation from the 2014 ISUP consensus conference endorsed in the 2016 WHO classification is that the percentage of pattern 4 should be recorded in all Gleason score $7(3+4,4+3)$ cases. ${ }^{1}$ This measurement further stratifies Gleason score 7 and allows identification of cases with limited pattern 4 (eg, less than 10\%) or extensive pattern 4 (eg, greater than $75 \%){ }^{14,15}$ This has practical importance since selected patients with Gleason score 7(3+4) but small amounts of pattern 4 (less than or equal to 10\%) may be eligible for active surveillance. ${ }^{16-17}$

In tumors with Gleason scores greater than 7, the percentage of patterns 4 and 5 has been shown to be of prognostic significance ${ }^{14}$ and may be included in the report. Currently there is no consensus on how the percentage of pattern $4+5$ should be recorded although it may be captured in $10 \%$ intervals or other stratifications such as less than 5\%, 5\%-10\%, 10\%-25\%, 25\%-50\%, 50\%-75\%, greater than $75 \%$. 
References

1. Humphrey P, Amin MB, Berney D, Billis A, et al. Acinar adenocarcinoma. In: Moch H, Humphrey PA, Ulbright T, Reuter VE, eds. Pathology and Genetics: Tumors of the Urinary System and Male Genital Organs. 4th edition. WHO Classification of Tumors. Zurich, Switzerland: WHO Press; 2015:3-28.

2. Gleason DR, Mellinger GT, the Veterans Administration Cooperative Urological Research Group. Prediction of prognosis for prostate adenocarcinoma by combined histological grading and clinical staging. J Urol. 1974;111:58-64.

3. Stephenson AJ, Scardino PT, Eastham JA, et al. Preoperative nomogram predicting the 10-year probability of prostate cancer recurrence after radical prostatectomy. J Natl Cancer Inst. 2006;98:715-717.

4. Stephenson AJ, Scardino PT, Eastham JA, et al. Postoperative nomogram predicting the 10-year probability of prostate cancer recurrence after radical prostatectomy. J Clin Oncol. 2005;23:7005-7012.

5. Makarov DV, Trock BJ, Humphreys EB, et al. Updated nomogram to predict pathologic stage of prostate cancer given prostate-specific antigen level, clinical stage, and biopsy Gleason score (Partin tables) based on cases from 2000 to 2005. Urology. 2007;69:1095-1101.

6. Epstein JI, Allsbrook Jr WC, Amin MB, Egevad L, ISUP Grading Committee. The 2005 International Society of Urological Pathology (ISUP) Consensus Conference on Gleason Grading of Prostatic Carcinoma. Am J Surg Pathol. 2005;29:1228-1242.

7. Epstein JI, Egevad L, Amin MB, Delahunt B, Srigley JR, Humphrey PA; and the Grading Committee The 2014 International Society of Urological Pathology (ISUP) Consensus Conference on Gleason Grading of Prostatic Carcinoma: definition of grading patterns and proposal for a new grading system. Am J Surg Pathol. 2016; 40: 244-252.

8. Pierorazio PM, Walsh PC, Partin AW, Epstein JI. Prognostic Gleason grade grouping: data based on the modified Gleason scoring system. BJU Int. 2013;111:753-760.

9. Eifler JB, Feng Z, Lin BM, Partin MT, Humphreys EB, Han M, et al. An updated prostate cancer staging nomogram (Partin tables) based on cases from 2006 to 2011. BJU Int. 2013;111:22-29.

10. Epstein JI, Zelefsky MJ, Sjoberg DD, et al. A contemporary prostate cancer grading system: a validated alternative to the Gleason score. Eur Urol. 2016;69:428-435.

11. Delahunt B, Egevad L, Srigley JR, et al. Validation of International Society of Urological Pathology (ISUP) grading for prostatic adenocarcinoma in thin core biopsies using TROG 03.04 'RADAR' trial clinical data. Pathology. 2015;47:520-525.

12. Samaratunga H, Delahunt B, Gianduzzo T, et al. The prognostic significance of the 2014 International Society of Urological Pathology (ISUP) grading system for prostate cancer. Pathology. 2015;47:515-519.

13. Berney DM, Beltran L, Fisher G, et al. Validation of a contemporary prostate cancer grading system using prostate cancer death as outcome. Br J Cancer. 2016;114(10):1078-1083.

14. Sauter G, Steurer S, Clauditz TS, et al. Clinical Utility of Quantitative Gleason Grading in Prostate Biopsies and Prostatectomy Specimens. Eur Urol. 2016;69:592-598.

15. Choy B, Pearce SM, Anderson BB, et al. Prognostic significance of percentages and architectural types of contemporary Gleason pattern 4 prostate cancer in radical prostatectomy. Am J Surg Pathol. 2016;40:14001406.

16. Morash C, Tey R, Agbassi C, Klotz L, McGowan T, Srigley A, Evans A. Active surveillance for the management of localized prostate cancer: guideline recommendations. Can Urol J Assoc. 2015;9(5-6):171178.

17. Chen RC, Rumble RB, Loblaw DA, et al. Active surveillance for the management of localized prostate cancer (Cancer Care Ontario Guideline): American Society of Clinical Oncology practice guideline endorsement. $J$ Clin Oncol. 2016;34(18):2182-2190.

\section{Intraductal Carcinoma (IDC)}

The presence of intraductal carcinoma (IDC) is important to record since it has independent prognostic significance. It is important to distinguish IDC from high-grade prostatic intraepithelial neoplasia. The differential diagnosis of IDC is beyond the scope of this protocol. IDC is strongly associated with high Gleason score and high volume tumor in radical prostatectomies and with metastatic disease ${ }^{1-3}$ At the 2014 ISUP consensus conference, it was agreed that Gleason scores or grade groups (ISUP grades) should not be assigned to IDC. ${ }^{4}$

References

1. Zhou M. Intraductal carcinoma of the prostate: the whole story. Pathology. 2013;45(6):533-539. 
2. Zhao $\mathrm{T}$, Liao B, Yao J, et al. Is there any prognostic impact of intraductal carcinoma of prostate in initial diagnosed aggressively metastatic prostate cancer? Prostate. 2015;75(3):225-232.

3. Van der Kwast T, Al Daoud N, Collette L, et al. Biopsy diagnosis of intraductal carcinoma is prognostic in intermediate and high risk prostate cancer patients treated by radiotherapy. Eur J Cancer. 2012;48(9):13181325.

4. Epstein JI, Egevad L, Amin MB, Delahunt B, Srigley JR, Humphrey PA; and the Grading Committee The 2014 International Society of Urological Pathology (ISUP) Consensus Conference on Gleason Grading of Prostatic Carcinoma: definition of grading patterns and proposal for a new grading system. Am J Surg Pathol. 2016; 40: 244-252.

\section{E. Quantitation of Tumor}

Studies have shown prostate cancer volume is a prognostic factor, although the data are conflicting as to its independent prognostic significance. There are many methods of estimating the amount of tumor in prostatic specimens. ${ }^{1-3}$ In subtotal and radical prostatectomy specimens, the percentage of tissue involved by tumor can be "eyeballed" by simple visual inspection. ${ }^{4}$ Additionally, it may be possible to measure a dominant tumor nodule in at least 2 dimensions ${ }^{5}$ and/or to indicate the number of blocks involved by tumor out of the total number of prostatic blocks submitted.

\section{References}

1. Bismar TA, Lewis JS, JR, Vollmer RT, Humphrey PA. Multiple measures of carcinoma extent versus perineural invasion in prostate needle biopsy tissue in prediction of pathologic stage in a screening population. Am J Surg Pathol. 2003;27:432-440.

2. Amin M, Boccon-Gibod L, Egevad L, et al. Prognostic and predictive factors and reporting of prostate carcinoma in prostate needle biopsy specimens. (2004 WHO-sponsored International Consultation Consensus). Scand J Urol Nephrol. 2004;39(216 suppl):20-33.

3. Paner GP, Magi-Galluzzi C, Amin MB, Srigley JR: Adenocarcinoma of the prostate. In: Amin MB, Grignon DJ, Srigley JR, Eble JN,eds. Urological Pathology. Philadelphia, PA: Lippincott William \& Wilkins; 2014:559-673.

4. van der Kwast T, Amin M, Billis A, Epstein J, et al; The ISUP prostate consensus group. International Society of Urological Pathology (ISUP) Consensus Conference on Handling of Radical Prostatectomy Specimens: working group 2: T2 substaging and prostate cancer volume. Mod Pathol. 2011;24:16-25.

5. Renshaw AA, Richie JP, Loughlin KR, Jiroutek M, Chung A, D'Amico AV. Maximum diameter of prostatic carcinoma is a simple, inexpensive, and independent predictor of prostate-specific antigen failure in radical prostatectomy specimens: validation in a cohort of 434 patients. Am J Clin Pathol. 1999;111:641-644.

\section{F. Extraprostatic Extension}

Extraprostatic extension (EPE) is the preferred term for the presence of tumor beyond the confines of the prostate gland. ${ }^{1-5}$ Tumor admixed with fat constitutes extraprostatic extension. Tumor involving loose connective tissue in the plane of fat or beyond, even in the absence of direct contact between the tumor and the adipocytes, indicates EPE. Extraprostatic extension may also be reported when the tumor involves perineural spaces in the neurovascular bundles, even in the absence of periprostatic fat involvement. In certain locations, such as the anterior and apical prostate and bladder neck regions, there is a paucity of fat, and in these locations, EPE is determined when the tumor extends beyond the confines of the normal glandular prostate. In the distal apical perpendicular margin section, it is often difficult to identify EPE. Sometimes there is a distinct bulging tumor nodule, which may be associated with a desmoplastic stromal reaction. The specific location(s) and the number of sites (blocks) of EPE are useful to report. Descriptors of EPE (focal versus nonfocal) should be used. ${ }^{1,2,5}$ Focal EPE equates with only a few neoplastic glands being outside the prostate or a tumor involving less than 1 highpower field in 1 or 2 sections; nonfocal EPE is more extensively spread beyond the prostatic edge.

\section{References}

1. Paner GP, Magi-Galluzzi C, Amin MB, Srigley JR: Adenocarcinoma of the prostate. In: Amin MB, Grignon DJ, Srigley JR, Eble JN,eds. Urological Pathology. Philadelphia, PA: Lippincott William \& Wilkins; 2014:559-673.

2. Srigley JR. Key issues in handling and reporting radical prostatectomy specimens. Arch Pathol Lab Med. 2006;30:303-317.

3. Ohori M, Kattan M, Scardino PT, Wheeler TM. Radical prostatectomy for carcinoma of the prostate. Mod Pathol. 2004;17:349-359. 
4. Epstein JI, Amin M, Boccon-Gibod L, et al. Prognostic factors and reporting of prostate carcinoma in radical prostatectomy and pelvic lymphadenectomy specimens. Scand J Urol Nephrol. 2005;216(suppl):34-63.

5. Magi-Galluzzi C, Evans A, Epstein J, et al; The ISUP prostate consensus group. International Society of Urological Pathology (ISUP) Consensus Conference on Handling and Staging of Radical Prostatectomy Specimens: Working group 3: extraprostatic extension lymphovascular invasion and locally advanced disease. Mod Pathol. 2011;24:26-38.

\section{G. Urinary Bladder Neck Invasion}

Invasion of the urinary bladder neck is identified when neoplastic glands involve the thick intersecting smooth muscle bundles characteristic of the bladder neck region in the absence of associated benign prostate tissue..$^{1-3}$ Microscopic bladder neck involvement is a significant predictor of prostate-specific antigen (PSA) recurrence, at least in univariate analysis ${ }^{3-5}$ and is considered as a criterion for category pT3a disease (AJCC $8^{\text {th }}$ edition). ${ }^{6}$

\section{References}

1. Magi-Galluzzi C, Evans A, Epstein J, et al; The ISUP prostate consensus group. International Society of Urological Pathology (ISUP) Consensus Conference on Handling and Staging of Radical Prostatectomy Specimens: Working group 3: extraprostatic extension lymphovascular invasion and locally advanced disease. Mod Pathol. 2011;24:26-38.

2. Pierorazio PM, Epstein JI, Humphreys E, Han M, Walsh PC and Partin AW. The significance of a positive bladder neck margin after radical prostatectomy: the American Joint Committee on Cancer Pathological Stage T4 designation is not warranted. $J$ Urol. 2010;183:151-157.

3. Zhou M, Reuther AM, Levin HS, Falzarano SM, Kodjoe E, Myles J, Klein E and Magi-Galluzzi C. Microscopic bladder neck involvement by prostate carcinoma in radical prostatectomy specimens is not a significant independent prognostic factor. Mod Pathol. 2009;22(3):385-392.

4. Dash A, Sanda MG, Yu M, Taylor JM, Fecko A, Rubin MA. Prostate cancer involving the bladder neck: recurrence-free survival and implications for AJCC staging modification. American Joint Committee on Cancer. Urology. 2002;60(2):276-280.

5. Yossepowitch O, Engelstein D, Konichezky M, Sella A, Livne PM and Baniel J. Bladder neck involvement at radical prostatectomy: positive margins or advanced T4 disease? Urology. 2000;56(3):448-452.

6. Amin MB, Edge SB, Greene FL, et al. eds. AJCC Cancer Staging Manual. $8^{\text {th }}$ ed. New York, NY: Springer; 2017.

\section{H. Seminal Vesicle Invasion}

Seminal vesicle invasion is a significant adverse prognostic factor associated with increased risk of PSA recurrence. ${ }^{1}$ There are different mechanisms of seminal vesicle invasion including: (1) direct invasion of the seminal vesicle from the base of the prostate; (2) extraprostatic extension prostate with subsequent invasion of seminal vesicle walls; (3) involvement along the ejaculatory duct into the seminal vesicle; and (4) discontinuous involvement, the latter which likely represents vascular spread. ${ }^{2}$ Seminal vesicle involvement is defined as a tumor invasion of the muscular wall of seminal vesicle. Only extraprostatic seminal vesicle invasion is included in the definition of seminal vesicle involvement. ${ }^{1}$ Intraprostatic seminal vesicle and ejaculatory duct can be difficult to separate from one another, and involvement of these structures is not considered pT3b disease.

\section{References}

1. Berney D, Wheeler T, Grignon D, et al; The ISUP prostate consensus group. International Society of Urological Pathology (ISUP) Consensus Conference on Handling and Staging of Radical Prostatectomy Specimens: Working group 4: seminal vesicles and lymph nodes. Mod Pathol. 2011;24:39-47.

2. Ohori M, Scardino PT, Lapin SL, Seale-Hawkins C, Link J, Wheeler TM. The mechanisms and prognostic significance of seminal vesicle involvement by prostate cancer. Am J Surg Pathol. 1993;17:1252-1261.

\section{Perineural Invasion}

Perineural invasion has been found to be an independent risk factor, in some studies, for predicting an adverse outcome in patients treated with external beam radiation, ${ }^{1}$ but not for patients treated with brachytherapy or radical prostatectomy. ${ }^{2}$ The value of perineural invasion as an independent prognostic factor has been questioned in a multivariate analysis. ${ }^{3}$ 


\section{References}

1. Yu HH, Song DY, Tsai YY, Thompson T, Frassica DA, DeWeese TL. Perineural invasion affects biochemical recurrence-free survival in patients with prostate cancer treated with definitive external beam radiotherapy. Urology. 2007;70:111-116.

2. O'Malley KJ, Pound CR, Walsh PC, Epstein JI, Partin AW. Influence of biopsy perineural invasion on longterm biochemical disease-free survival after radical prostatectomy. Urology. 2002;59:85-90.

3. Harnden $\mathrm{P}$, Shelley MD, Clements $\mathrm{H}$, et al. The prognostic significance of perineural invasion in prostatic carcinoma biopsies: a systematic review. Cancer. 2007;109:13-24.

\section{J. Margins}

Margin positivity is a significant adverse prognostic factor. ${ }^{1}$ To properly evaluate surgical margins, the entire surface of the prostate should be inked. ${ }^{2-4}$ The apex should be carefully examined because it is a common site of margin positivity. ${ }^{5-11}$ At the apex, tumor admixed with skeletal muscle elements does not constitute extraprostatic extension. The apical and bladder neck surgical margins should be submitted entirely, preferably with a perpendicular sectioning technique..$^{2-4}$ Usually, surgical margins should be designated as "negative" if tumor is not present at the inked margin and as "positive" if tumor cells touch the ink at the margin. When tumor is located very close to an inked surface but is not actually in contact with the ink, the margin is considered negative. Positive surgical margins should not be interpreted as extraprostatic extension. Intraprostatic margins are positive in the setting of intraprostatic or capsular incision (so-called pT2+ disease; Figure 2). ${ }^{1,3}$ If the surgical margin finding is positive, the pathologist should state that explicitly, although this finding is not relied upon for pathologic staging. The specific locations of the positive margins should be reported. There should be some indication of the extent of margin positivity. At the 2009 International Society of Urological Pathology Consensus Conference on Handling and Staging of Radical Prostatectomy Specimens, it was recommended that the extent of a positive margin should be reported as millimeters of involvement. ${ }^{1}$

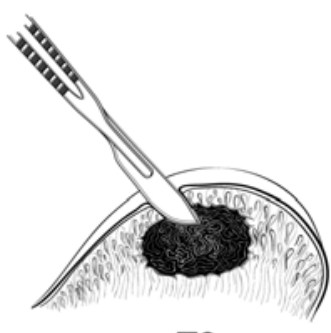

pT2

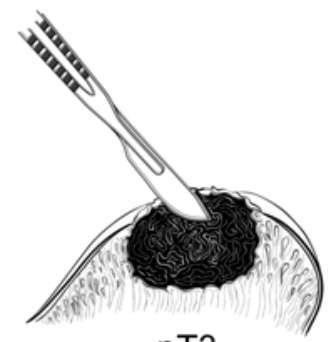

pT3
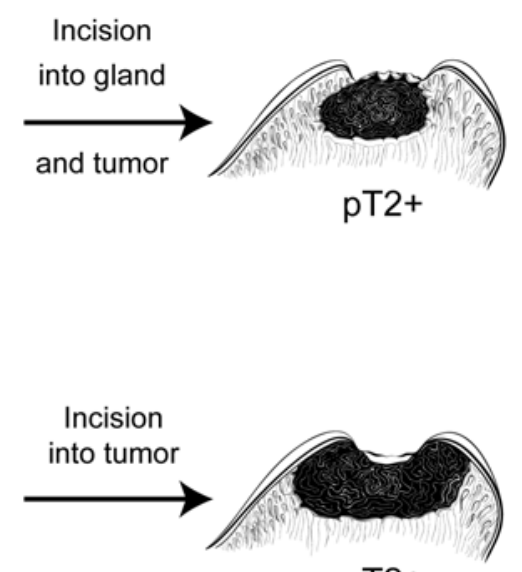

pT2+

Figure 2. Surgical incision can create stage pT2+ from either pT2 or pT3 disease.

It is also important to indicate whether the positive margin is incisional or in an area of EPE. The latter has more adverse prognostic significance than the former. ${ }^{1}$

Recent studies suggest that the Gleason grade or score at a site of margin positivity is correlated with biochemical recurrence..$^{12-15}$ The presence of any pattern 4 or 5 in tumor at a margin doubled the risk of PSA recurrence compared to only Gleason pattern 3 at margin. ${ }^{12}$ From a practical perspective the documentation of the highest pattern present at a positive surgical margin is reasonable 


\section{References}

1. Tan, PH, Cheng L, Srigley J, et al; The ISUP prostate consensus group. International Society of Urological Pathology (ISUP) Consensus Conference on Handling and Staging of Radical Prostatectomy Specimens: Working Group 5: Surgical margins. Mod Pathol. 2011;24:48-57.

2. Paner GP, Magi-Galluzzi C, Amin MB, Srigley JR: Adenocarcinoma of the prostate. In: Amin MB, Grignon DJ, Srigley JR, Eble JN,eds. Urological Pathology. Philadelphia, PA: Lippincott William \& Wilkins; 2014:559-673.

3. Srigley JR. Key issues in handling and reporting radical prostatectomy specimens. Arch Pathol Lab Med. 2006;30:303-317.

4. Samarantunga $\mathrm{H}$, Montironi $\mathrm{R}$, True L, et al; The ISUP prostate consensus group. International Society of Urological Pathology (ISUP) Consensus Conference on Handling and Staging of Radical Prostatectomy Specimens: Working group 1: handling of the specimen. Mod Pathol. 2011;24:6-15.

5. Amin MB, Lin DW, Gore JL, et al. The critical role of the pathologist in determining eligibility for active surveillance as a management option in patients with prostate cancer: consensus statement with recommendations supported by The College of American Pathologists, International Society of Urological Pathology, Association of Directors of Anatomical and Surgical Pathology, The New Zealand Society of Pathologists and the Prostate Cancer Foundation. Arch Pathol Lab Med. 2014;138:1387-1405.

6. Fontugne J, Davis K, Palanisamy N, et al. Clonal evaluation of prostate cancer foci in biopsies with discontinuous tumor involvement by dual ERG/SPINK1 immunohistochemistry. Mod Pathol. 2016;29(2):157165.

7. Arias-Stella JA 3rd, Varma KR, Montoya-Cerrillo D, Gupta NS, Williamson SR. Does discontinuous involvement of a prostatic needle biopsy core by adenocarcinoma correlate with a large tumor focus at radical prostatectomy? Am J Surg Pathol. 2015;39(2):281-286.

8. Karram S, Trock BJ, Netto GJ, Epstein Jl. Should intervening benign tissue be included in the measurement of discontinuous foci of cancer on prostate needle biopsy? Correlation with radical prostatectomy findings. Am J Surg Pathol. 2011;35(9):1351-1355.

9. van der Kwast T, Amin M, Billis A, Epstein J, et al; The ISUP prostate consensus group. International Society of Urological Pathology (ISUP) Consensus Conference on Handling of Radical Prostatectomy Specimens: working group 2: T2 substaging and prostate cancer volume. Mod Pathol. 2011;24:16-25.

10. Renshaw AA, Richie JP, Loughlin KR, Jiroutek M, Chung A, D'Amico AV. Maximum diameter of prostatic carcinoma is a simple, inexpensive, and independent predictor of prostate-specific antigen failure in radical prostatectomy specimens: validation in a cohort of 434 patients. Am J Clin Pathol. 1999;111:641-644.

11. Ohori M, Scardino PT, Lapin SL, Seale-Hawkins C, Link J, Wheeler TM. The mechanisms and prognostic significance of seminal vesicle involvement by prostate cancer. Am J Surg Pathol. 1993;17:1252-1261.

12. Savdie R, Horvath LG, Benito RP, et al. High Gleason grade carcinoma at a positive surgical margin predicts biochemical failure after radical prostatectomy and may guide adjuvant radiotherapy. BJU Int. 2010;109:17941800.

13. Brimo F, Partin AW and Epstein Jl. Tumor grade at margins of resection in radical prostatectomy specimens is an independent predictor of prognosis. Urology. 2010;76:1206-1209.

14. Cao D, Kibel AS, Gao F, Tao Y and Humphrey PA. The Gleason score of tumor at the margin in radical prostatectomy specimens is predictive of biochemical recurrence. Am J Surg Pathol. 2010;34:994-1001.

15. Kates M, Sopko NA, Han M, Partin AW and Epstein JI. Importance of reporting the Gleason score at the positive surgical margin site: an analysis of 4,082 consecutive radical prostatectomy cases. J Urol. 2015.

\section{K. TNM and Stage Groupings}

The protocol recommends the use of the TNM Staging System for carcinoma of the prostate of the American Joint Committee on Cancer (AJCC). ${ }^{1}$

By AJCC convention, the designation " $T$ " refers to a primary tumor that has not been previously treated. The symbol "p" refers to the pathologic classification of the TNM, as opposed to the clinical classification, and is based on gross and microscopic examination. pT entails a resection of the primary tumor or biopsy adequate to evaluate the highest pT category, pN entails removal of nodes adequate to validate lymph node metastasis, and pM implies microscopic examination of distant lesions. Clinical classification (cTNM) is usually carried out by the referring physician before treatment during initial evaluation of the patient or when pathologic classification is not possible. 
Pathologic staging is usually performed after surgical resection of the primary tumor. Pathologic staging depends on pathologic documentation of the anatomic extent of disease, whether or not the primary tumor has been completely removed. If a biopsied tumor is not resected for any reason (eg, when technically unfeasible), and if the highest $\mathrm{T}$ and $\mathrm{N}$ categories or the M1 category of the tumor can be confirmed microscopically, the criteria for pathologic classification and staging have been satisfied without total removal of the primary cancer. Tumor confined to the prostate gland irrespective of amount and distribution is considered pT2. pT3a and pT3b are illustrated in Figure $3 .^{1}$

T3a

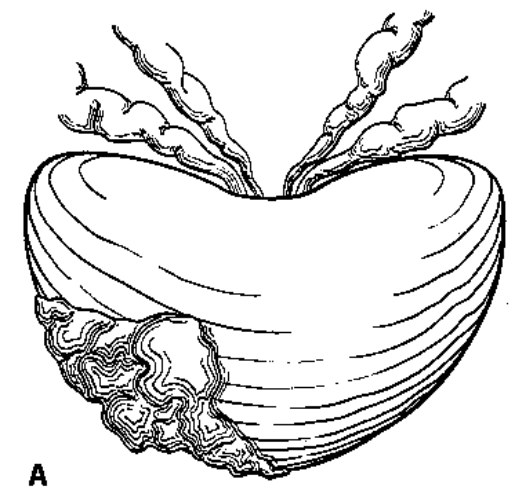

T3a

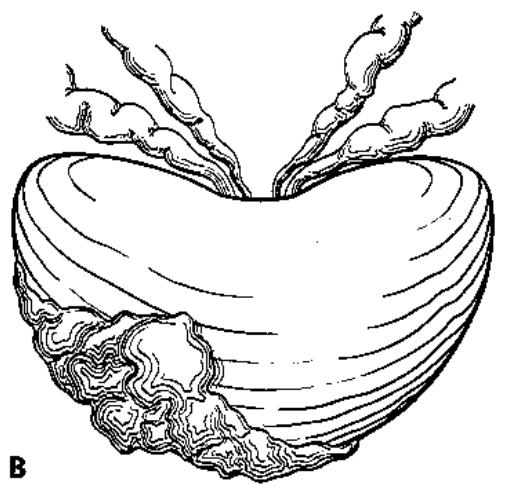

T3b

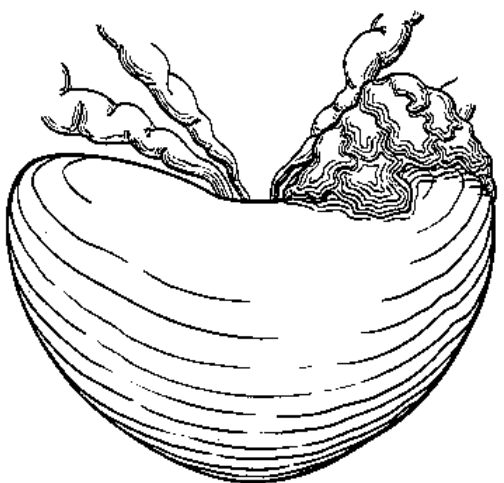

Figure 3. T3a is defined as a tumor with unilateral extraprostatic extension, as shown in A, or with bilateral extension, as shown in B. Microscopic extension into the bladder neck is also pT3a. T3b tumor invading the seminal vesicle. Used with permission of the American Joint Committee on Cancer (AJCC), Chicago, III. ${ }^{1}$

\section{Regional and Distant Lymph Nodes}

Regional Lymph Nodes

The regional lymph nodes are the nodes of the true pelvis, which essentially are the pelvic nodes below the bifurcation of the common iliac arteries. They include the following groups:

- Pelvic, NOS

- Hypogastric

- Obturator

- $\quad$ lliac (internal, external, or NOS)

- $\quad$ Sacral (lateral, presacral, promontory [Gerota's], or NOS)

Laterality does not affect the $\mathrm{N}$ classification.

\section{Distant Lymph Nodes}

Distant lymph nodes lie outside the confines of the true pelvis. They can be imaged using ultrasound, computed tomography, magnetic resonance imaging, or lymphangiography. Although enlarged lymph nodes can occasionally be visualized on radiographic imaging, fewer patients are initially discovered with clinically evident metastatic disease. In lower risk patients, imaging tests have proven unhelpful. In lieu of imaging, risk tables are many times used to determine individual patient risk of nodal involvement prior to therapy. Involvement of distant lymph nodes is classified as M1a. The distant lymph nodes include the following:

- Aortic (paraaortic lumbar)

- Common iliac

- Inguinal, deep

- Superficial inguinal (femoral)

- Supraclavicular

- Cervical

- Scalene

- Retroperitoneal, NOS

\section{TNM Descriptors}

For identification of special cases of TNM or pTNM classifications, the "m" suffix and the "y," "r," and "a" prefixes are used. Although they do not affect the stage grouping, they indicate cases needing separate analysis. 
The " $m$ " suffix indicates the presence of multiple primary tumors in a single site and is recorded in parentheses: pT(m)NM.

The "y" prefix indicates those cases in which classification is performed during or following initial multimodality therapy (ie, neoadjuvant chemotherapy, radiation therapy, or both chemotherapy and radiation therapy). The cTNM or pTNM category is identified by a "y" prefix. The ycTNM or ypTNM categorizes the extent of tumor actually present at the time of that examination. The "y" categorization is not an estimate of tumor prior to multimodality therapy (ie, before initiation of neoadjuvant therapy).

The "r" prefix indicates a recurrent tumor when staged after a documented disease-free interval, and is identified by the "r" prefix: rTNM.

The "a" prefix designates the stage determined at autopsy: aTNM.

Lymphovascular Invasion

Lymphovascular invasion (LVI) indicates whether microscopic lymph-vascular invasion is identified. LVI includes lymphatic invasion, vascular invasion, or lymphovascular invasion. By AJCC convention, LVI does not affect the T category indicating local extent of tumor unless specifically included in the definition of a T category.

\section{References}

1. Amin MB, Edge SB, Greene FL, et al, eds. AJCC Cancer Staging Manual. $8^{\text {th }}$ ed. New York, NY: Springer; 2017. 